International Journal of Engineering, Science and Technology

Vol. 3, No. 5, 2011, pp. 59-72
INTERNATIONAL JOURNAL OF ENGINEERING, SCIENCE AND TECHNOLOGY

WWW.ijest-ng.com

(C) 2011 Multicraft Limited. All Rights Reserved

\title{
Numerical prediction of wind loads on low buildings
}

\author{
S. Ahmad ${ }^{*}$, M. Muzzammil ${ }^{2}$, I. Zaheer ${ }^{3}$ \\ ${ }^{I *}$ Department of Civil Engineering, Aligarh Muslim University, Aligarh. INDIA \\ ${ }^{2}$ Department of Civil Engineering, Aligarh Muslim University, Aligarh, INDIA \\ ${ }^{3}$ Department of Civil Engineering, Aligarh Muslim University, Aligarh, INDIA \\ ${ }^{*}$ Corresponding Author: e-mail: shakeel60in@yahoo.co.in, Tel:(0571)2720256; Mob: 9412877550
}

\begin{abstract}
In the present study, 2-D numerical simulation of wind loads on low-rise buildings has been carried out. The simulation was carried out under FLUENT package environment in which full-scale Reynolds number, boundary layer and turbulence properties have been simulated. Wind loading effect numerically obtained on flat roof (TTU building) and pitched roof is compared with wind tunnel data. It was found that there is fair agreement between the numerical predictions and measurements for time-averaged wind loads on buildings. The computed pressure coefficients have been validated with wind tunnel TTU building model results on 1:100 scale within an average error of $20 \%$. The effect of roof pitch for $10^{\circ}, 20^{\circ} \& 30^{\circ}$ on pressure coefficients for gable roof has also been investigated and the results were compared with the available wind tunnel results for $15^{\circ}, 26^{\circ} \& 35^{\circ}$ roof pitch. The present study shows that the numerical simulation of wind loads hold a great potential for extending codes of practice for wind loads.
\end{abstract}

Key words: low-rise buildings, wind loads, numerical simulation, gable roof, TTU building.

\section{Introduction}

Building designers usually determine wind loads on buildings with reference to codes of practice, which in turn are usually based on measurements in boundary layer wind tunnels. Many cases are not treated in these codes, making wind-tunnel measurements necessary to determine the wind loads. However, few building designers have easy access to such tunnels. Wind-tunnel tests can further be laborious and expensive and it is impossible to simulate the full-scale Reynolds numbers (Re). It may also be difficult to simulate the atmospheric turbulence properties and boundary layer for complex terrains. Numerical prediction of wind loads offers certain advantages over the use of scale models in boundary layer wind tunnels. For example, any Reynolds number, turbulence and boundary layer profile can be simulated. It is also convenient to do parametric studies with a numerical procedure, as the boundary conditions can be changed with ease. Numerical simulations therefore hold great potential for extending codes of practice. The accuracy of predictions depends primarily on proper choice of boundary conditions, accuracy of discretization methods and most important of all, the proper choice of turbulence model. Many researchers have made significant contributions in the field of computational wind engineering in the past four decades.

Mathews (1987) used computational methods to predict wind-generated pressure distributions around buildings. These pressure distributions were needed for the prediction of natural ventilation in the buildings. The accuracy of the predicted pressure distribution was found to be acceptable. Mathews and Mayer (1987) observed that the prediction of wind loads on greenhouses is essential to their safe design. Numerically predicted wind loads on a semicircular greenhouse were presented. Parametric studies of the influences of Reynolds number and terrain roughness on the wind induced pressure distribution around the greenhouse were also reported. The pressure distribution at high Reynolds numbers was compared with published full-scale measurements. Baskaran and Stathopoulos (1989) worked on computational evaluation of wind effects on buildings. A computer simulation of wind flow around a block-shaped building was attempted using 3-D turbulent flow conditions. The Control Volume Method was used for numerical discretization. The relevant comprehensive literature review on numerical prediction of wind loads based on RANS (Reynolds Average Navier Stokes) model, Large Eddy Simulation (LES) model and $k-\epsilon$ model are available elsewhere (Zaheer, 2007). Only a brief account on $k-\epsilon$ model is described herein as it has been used in the present study. 


\section{$1.1 k$ - $\varepsilon$ Model:}

Murakami (1990) did a numerical simulation of turbulent flow field around cubic model and applied $k-\varepsilon$ model and LES. The time-dependent flow field was predicted by 3D Large Eddy Simulation and the results were illustrated using the techniques of animated graphics. Crosby et al. (1990) used a turbulent two-dimensional flow simulation program to investigate wind-induced pressure loads on buildings. A newly developed model for flow through porous media was incorporated to investigate the effect of windbreaks. The results were successfully compared with wind tunnel measurements. Stathopoulos and Baskaran (1990) addressed the numerical computation of 3-D wind flow conditions around a building. Differential equations were discretized into different form using the control volume method. They examined the current boundary treatment methodologies and proposed a new procedure for boundary treatment with two variables involved in the computation. For most of the cases in which the new method was employed, computed results agreed well with the measured wind-tunnel data. Stathopoulos and Saathoff (1991) carried out work to determine local pressure coefficients appropriate for the design of multi-span gabled (folded) roofs of low buildings. Murakami et al. (1992) did a numerical study on velocity-pressure field and wind forces for bluff bodies using three types of well-known turbulence models, namely $k-\varepsilon$ Eddy Viscosity Model ( $k-\varepsilon$ EVM), Algebraic Stress Model (ASM) and Large Eddy Simulation (LES). Three-dimensional (3D), time-averaged flow fields around a cube within a surface boundary layer were predicted using these three turbulence models with similar boundary conditions.

Stathopoulos and Zhou (1993) numerically predicted turbulent wind pressures on the surfaces of various buildings with sharp corners of right angles for different wind directions. The computer program developed for this purpose solved the time-averaged Navier-Stokes equations using the k- $\varepsilon$ turbulence model for closure. Computed pressures were compared with experimentally obtained values for a stepped-roof building (L-shaped in cross-section). Good agreement was found for normal wind directions while differences existed in oblique wind cases.

Sakamoto et al. (1993) analyzed unsteady velocity-pressure fields around an oscillating square prism by means of LES. The accuracy of the numerical results was assessed by comparing them with the experimental results. The results of LES showed a good agreement with the results of experiment, in terms of: (a) the phase angle between the displacement of the oscillating prism and the negative pressure acting on the side face, and (b) the correlation between pressures across the side face. Mochida et al. (1993) worked on numerical simulation of flow field around Texas Tech Building by Large Eddy Simulation. Velocity and pressure fields around the low-rise experimental building located at Texas Tech University were predicted. The distributions of mean and rms surface pressure coefficients predicted by LES were compared with those of field and wind tunnel measurements. The results of LES corresponded very well with the measured data. Murakami (1993) compared various turbulence models applied to a bluff body. Flow fields around bluff bodies, characterized by complex distributions of the strain-rate tensor, can be analyzed with various turbulence models. The shortcoming of the eddy viscosity modeling in the $k-\varepsilon$ model was scrutinized in comparison with the results of ASM. The accuracy of the algebraic approximation adopted in ASM was examined using the numerical data given from LES. He then presented a new LES model with variable Smagorinsky constant.

Further, Rodi (1993) extended the work on simulation of turbulent flow past bluff bodies. The experiences gathered with various statistical turbulence models ranging from algebraic eddy-viscosity models to Reynolds-stress-equation models were summarized and discussed, and calculations of vortex-shedding flow past cylinders of various cross-sections were presented. These calculations were then confronted with large-eddy simulations whenever possible, and a comparative discussion on the various calculation methods was given. Richards and Hoxey (1993) carried out work to determine appropriate boundary conditions for computational wind engineering models using the k- $\varepsilon$ turbulence model. Frank and Mauch (1993) used Large-eddy-simulation of the flow around building models. A numerical program package was described to calculate incompressible, unsteady, three-dimensional viscous and turbulent flow fields around sharp edged obstacles. Computation of wind flows around two tall buildings was done by Paterson and Papen fuss (1993) experimental results for wind flows around two tall buildings were compared with results from a computer simulation. The simulation used a steady-state solution method with a k- $\varepsilon$ model of turbulence. In the measured flow, the vortices shed from each building had a strong influence on pressures on and around the other building. Their research examined the accuracy of steady-state solution methods in the prediction of mean pressures in such flows.

Analyses by CFD on unsteady flow fields past a two-dimensional (2D) square cylinder was reviewed by Murakami \& Mochida (1995). Firstly, the comparison of the results of large eddy simulation (LES) for 2D and 3D computations were described. The LES results given from 3D computation agreed very well with the experimental results, but the results based on 2D computation were different from those based on 3D computation as well as from those given from experiments. Investigation regarding the numerical evaluation of wind pressures on flat roofs by using the Reynolds averaged Navier-Stokes equations and the standard $k-\varepsilon$ turbulence model was presented by Stathopoulos and Zhou (1995). A low and a taller building model were considered and wind blowing from different directions was assumed. Data were presented for roof edges and corners. Experimental measurements were also carried out in a boundary layer wind tunnel and results were compared with the computed data. Over most of the roof surface area, the comparisons were good for normal wind conditions and the low building model. Yu and Kareem (1996) worked on twodimensional simulation of flow around rectangular prisms. Frank (1996) performed numerical calculation for the turbulent flow fields at high Reynolds numbers by means of the LES. Kondo et al. (1997) studied inflow turbulence for LES, generated by the method of Hoshiya (1972) based on Monte Carlo simulation considering power spectral density and cross-spectral density as targets. Large eddy simulation of flow past a cubic obstacle was done by Shah and Ferziger (1997). They focused on LES in which the large scales of motion were computed explicitly while the small or sub grid-scale motions were modeled. Tsuchiya et al. (1997) proposed a new $k-E^{2}$ model which resolves these problems by modifying the expression for eddy viscosity approximation. They examined the applicability of this new $k-\varepsilon^{E}$ model (MMK model) to flow fields around three types of bluff bodies, i.e. a 2D 
square rib, a cube and a low-rise building model with 1: 1: 0.5 shape. Tominaga et al. (1997) predicted turbulent diffusion of gaseous contaminant near a cubic-shaped building model by LES using a Dynamic Mixed SGS (DM) model with the aid of the composite grid technique. Lakehal and Rodi (1997) calculated the flow past a surface-mounted cube with two-layer turbulence models. In 3-D steady calculation of the flow around a cube placed in developed-channel flow, various versions of the $k$ - $\varepsilon$ model were tested. Murakami et al (1997) worked on the CFD analysis of wind-structure interaction for oscillating square cylinders. They dealt with the interaction between fluid and body, i.e., the flow fields around oscillating square cylinders both in cases of forced oscillation and wind-induced free oscillation. Yu and Kareem (1998) performed a parametric study of flow around rectangular prisms using LES. The study on rectangular prisms of different aspect ratios (1:1,1:1.5, 1:2,1:3, and 1:4) was conducted numerically at a Reynolds number of $10^{5}$. The Navier-Stokes equations in the LES framework were solved using a finite volume method. Computational fluid dynamics analysis of turbulent flow past a square cylinder was conducted using LES by Murakami et al (1999). Nozawa and Tamura (2002) validated the LES technique for predicting a flow around an obstacle under the condition that a turbulent flow is approaching the obstacle. The turbulent inflow data were generated for both a smooth surface and rough surface. Ghosh (2004) reviewed the computational method used in solving wind engineering problems mainly related to wind flow over bluff bodies. Air approach flow moving towards a cube was studied using computational fluid dynamics by Gao and Chow (2005). Hoffman and Johnson (2006) presented a new approach to computational fluid dynamics using adaptive stabilized Galerkin finite element methods with duality based a posteriori error control for chosen output quantities of interest. Huang et al. (2007) did a comprehensive numerical study of wind effects on the Commonwealth Advisory Aeronautical Council (CAARC) standard tall building. The techniques of CFD, such as LES, RANS model etc., were adopted in this study to predict wind loads on and wind flows around the building.

\section{Present study}

In the present study, TTU building $(13.7 \mathrm{~m} \times 9.1 \mathrm{~m}$ in plan with $4.0 \mathrm{~m}$ eave height flat roof) on 1: 100 scale model (Cocharan, $1992)$ and the gable roof $(13.7 \mathrm{~m} \times 9.1 \mathrm{~m}$ in plan with $4.0 \mathrm{~m}$ eave height with roof slopes 108, 208 and 308) model have been chosen for numerical simulation for prediction of wind loads for normal angle of incidence. The software package FLUENT was used to analyze these building models. The data presented in the package is given in Table-1. The Flow chart diagram for computation of wind loads has been shown in Figure1. The grid and the flow patterns generated for the models are shown in Figures 2-6. The FLUENT package is based on the partial differential equations that govern the movement of viscous fluid i.e. the Navier-Stokes equations (Eq1) and the continuity equation (Eq. 2).

$\rho \frac{D V}{D t}=-\nabla P+\frac{\partial}{\partial x_{j}}\left[\mu\left(\frac{\partial v_{i}}{\partial x_{j}}+\frac{\partial v_{j}}{\partial x_{i}}\right)\right]$

$\nabla . V=0$

Where,

$\rho$ is density, $D / D t$ is the substantial derivative, $\mathrm{V}$ is the velocity vector, $\mathrm{P}$ is the pressure and $\mu$ is the effective viscosity.

For the simulation of turbulence in the flow, the $\kappa-\varepsilon$ turbulence viscosity model is employed. Values for $\kappa$ (turbulence kinetic energy) and $\varepsilon$ (dissipation rate of turbulence) were calculated from elliptical partial differential equations.

The power law was used to simulate the inflow u- velocity profile of the atmospheric boundary layer. Inflow values of v- velocities are set to zero while the inflow turbulence intensities $\mathrm{I}(\mathrm{y})$ at height $\mathrm{y}$ are simulated by the following empirical equation:

$\mathrm{I}(\mathrm{y})=\left(6.7 \mathrm{k}_{\mathrm{s}}\right)^{1 / 2} \mathrm{u}_{\mathrm{ref}} / \mathrm{u}(\mathrm{y})$

Where, $k_{s}$ is a surface roughness parameter which is a measure of the surface friction coefficient of the terrain. The mean horizontal wind speed $\mathrm{u}_{\mathrm{ref}}$ is measured at ridge height while $\mathrm{u}(\mathrm{y})$ is the mean horizontal wind speed distribution as a function of height $\mathrm{y}$, the turbulence intensity distribution can be stimulated at inflow by specifying appropriate values for $\mathrm{k}(\mathrm{y})$.

At inflow, the turbulence length scale $\mathrm{L}(\mathrm{y})$ at height $\mathrm{y}$ is given by the following equation:

$\mathrm{L}(\mathrm{y})=151(\mathrm{y} / 10)^{\alpha}$

At outflow, a zero gradient is used for all the variables. Both normal and tangential velocity values are set to zero at solid boundaries. The boundary conditions for turbulence properties near solid walls are described by certain wall functions. At free stream boundaries, flow is prohibited from crossing the boundaries, while a zero normal gradient is imposed on u-velocities and pressures.

In the present study, orthogonal grid systems on the buildings have been used for the solution of the governing finite difference equations. A flow domain having boundary at the distance of $20 \mathrm{~m}$ from inlet wall and $200 \mathrm{~m}$ from the top and rear walls is used in the solution for the TTU and gable roof buildings, have been shown respectively in Figs $2 \& 4$. The summary of the data required for computation through FLUENT is provided in Table-1.The results obtained in the present study have been compared with the Cocharan (1992) results on 1:100 scale model of TTU building whereas, for gable roof it has been compared with Mathews et al. (1988) numerical simulation results having model dimensions $21.3 \mathrm{~m} \times 6.4 \mathrm{~m} \times 3.9 \mathrm{~m}$ with roof slopes $15^{\circ}, 26^{\circ}$ and $35^{\circ}$. 


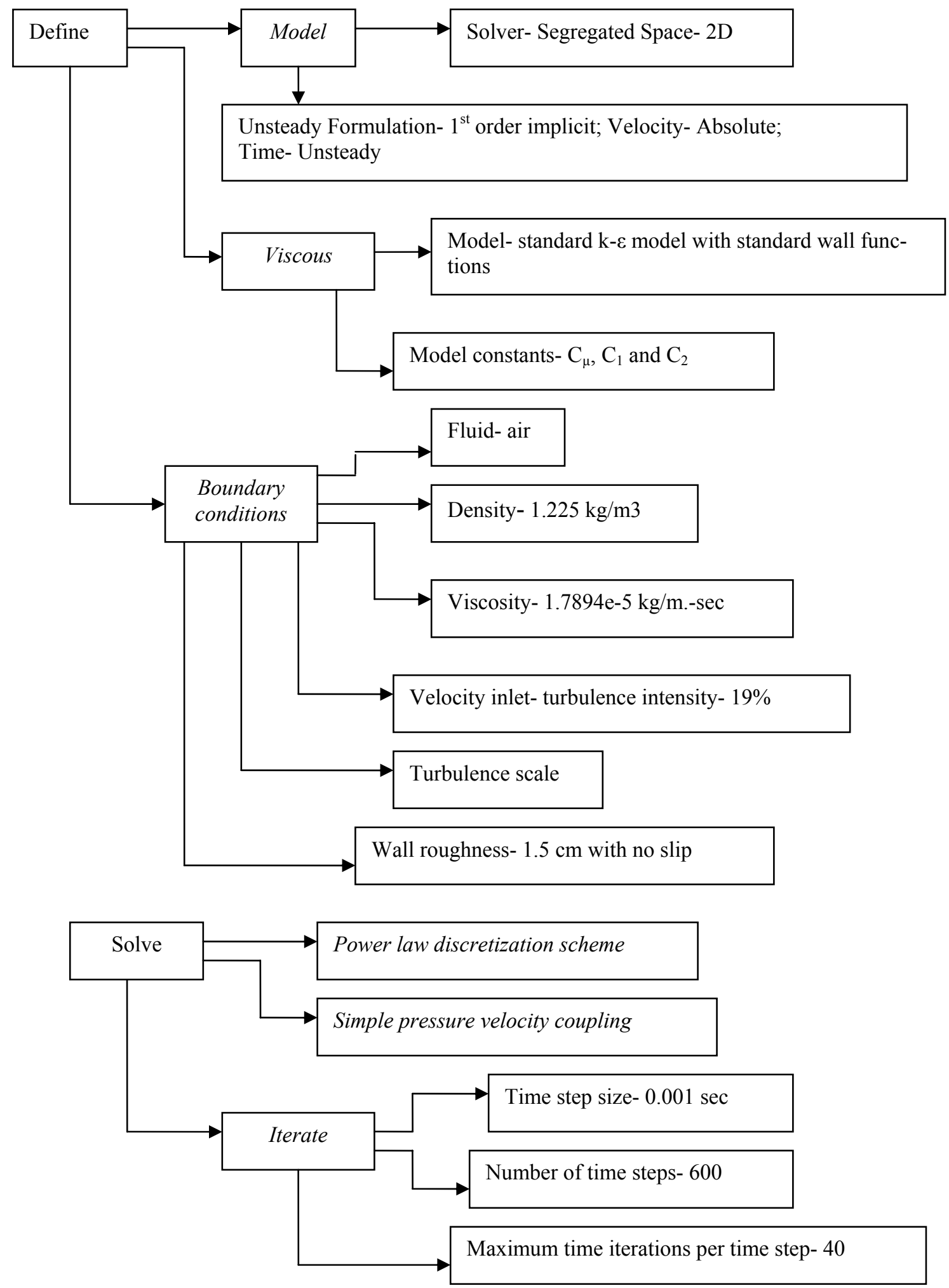

Figure 1 Flow Chart for Computation through FLUENT 
Table-1: Summary of data used in the FLUENT

\begin{tabular}{|c|c|c|}
\hline S.N. & Parameters & Values \\
\hline 1 & Mean Wind Speed $(\mathrm{m} / \mathrm{s})$ & 10.7 \\
\hline 2 & Power Law Coefficient, $\alpha$ & 0.14 \\
\hline 3 & Roughness Length, $z_{o}(\mathrm{~cm})$ & 1.50 \\
\hline 4 & Longitudinal Turbulence Intensity $(\%)$ & 19 \\
\hline 5 & Density of air $\left(\mathrm{kg} / \mathrm{m}^{3}\right)$ & 1.225 \\
\hline 6 & Viscosity of air $(\mathrm{kg} / \mathrm{m}-\mathrm{s})$ & $1.7594 \times 10^{-5}$ \\
\hline
\end{tabular}

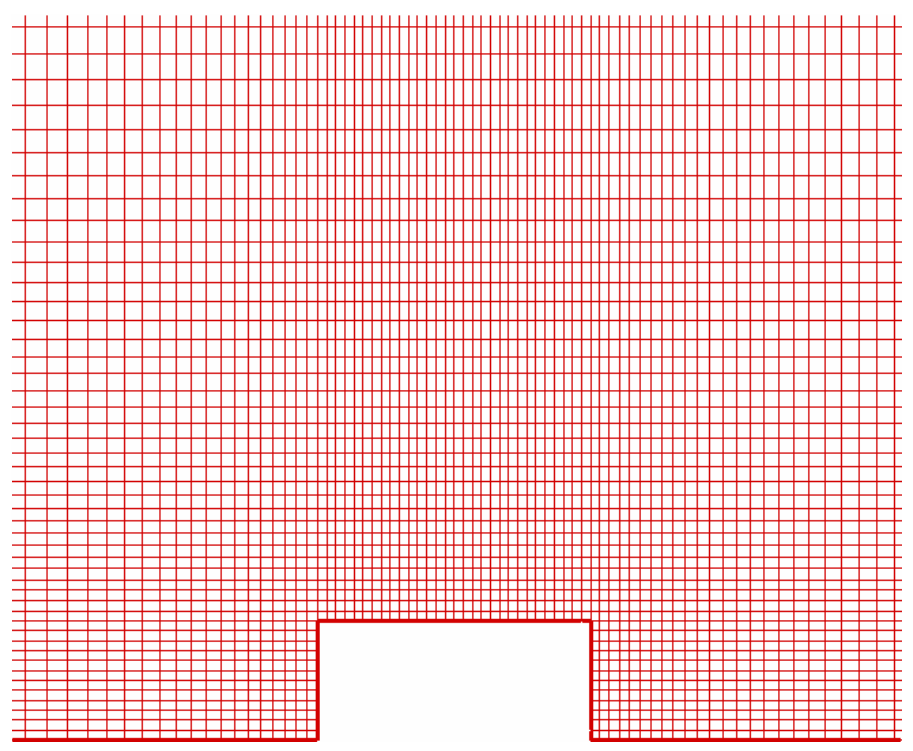

Figure 2 The Generated magnified Grid for Flat Roof

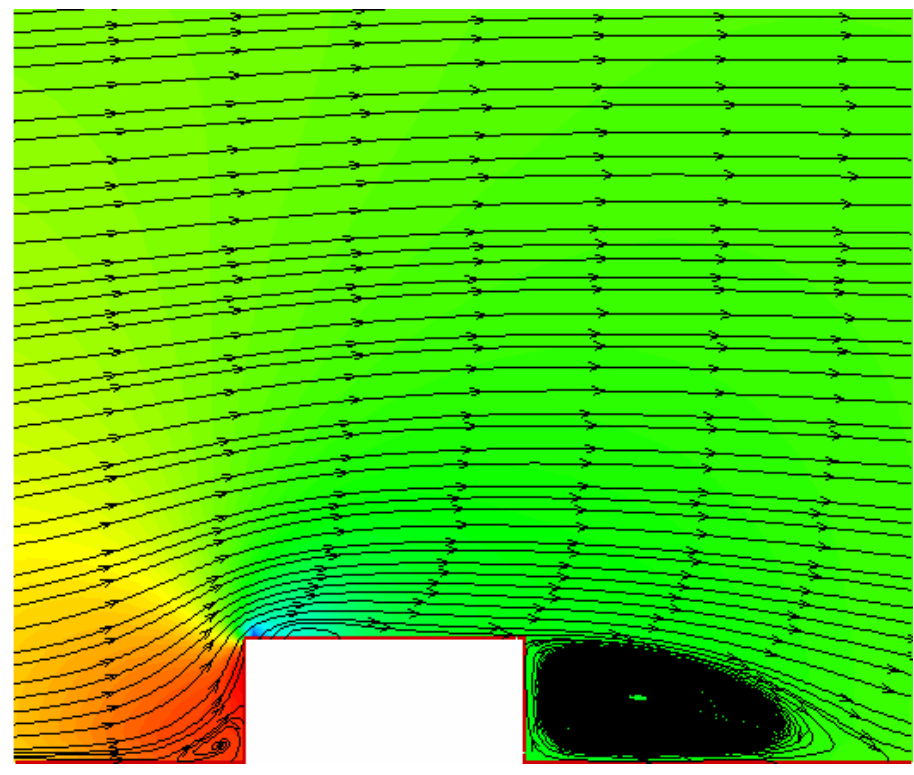

Figure 3 Simulated Streamlines for Flat Roof 


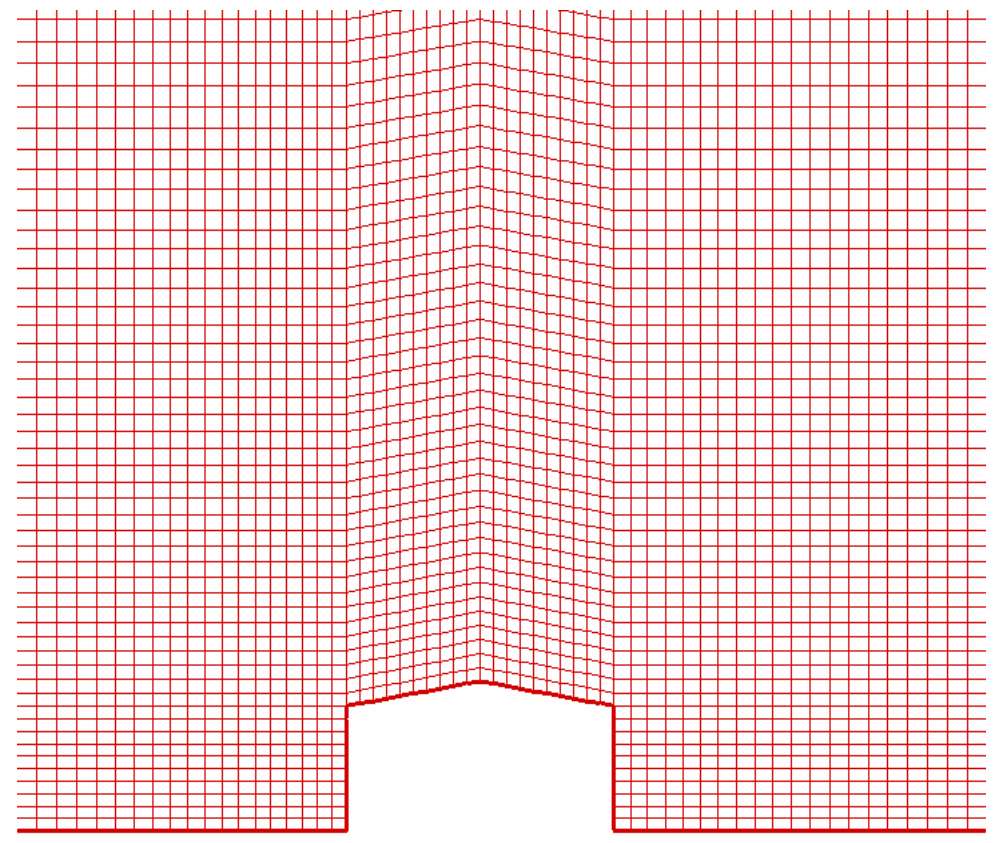

Figure 4 Generated Magnified Grid for Gable Roof

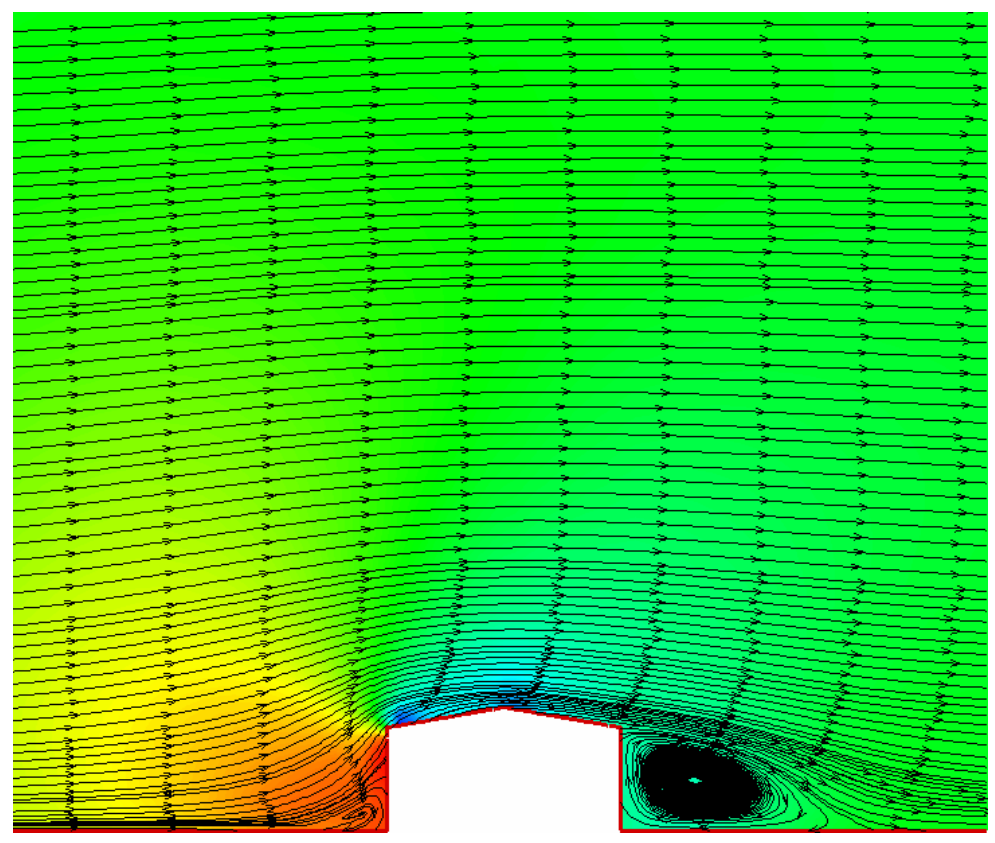

Figure 5 Generated Streamlines for Gable Roof 


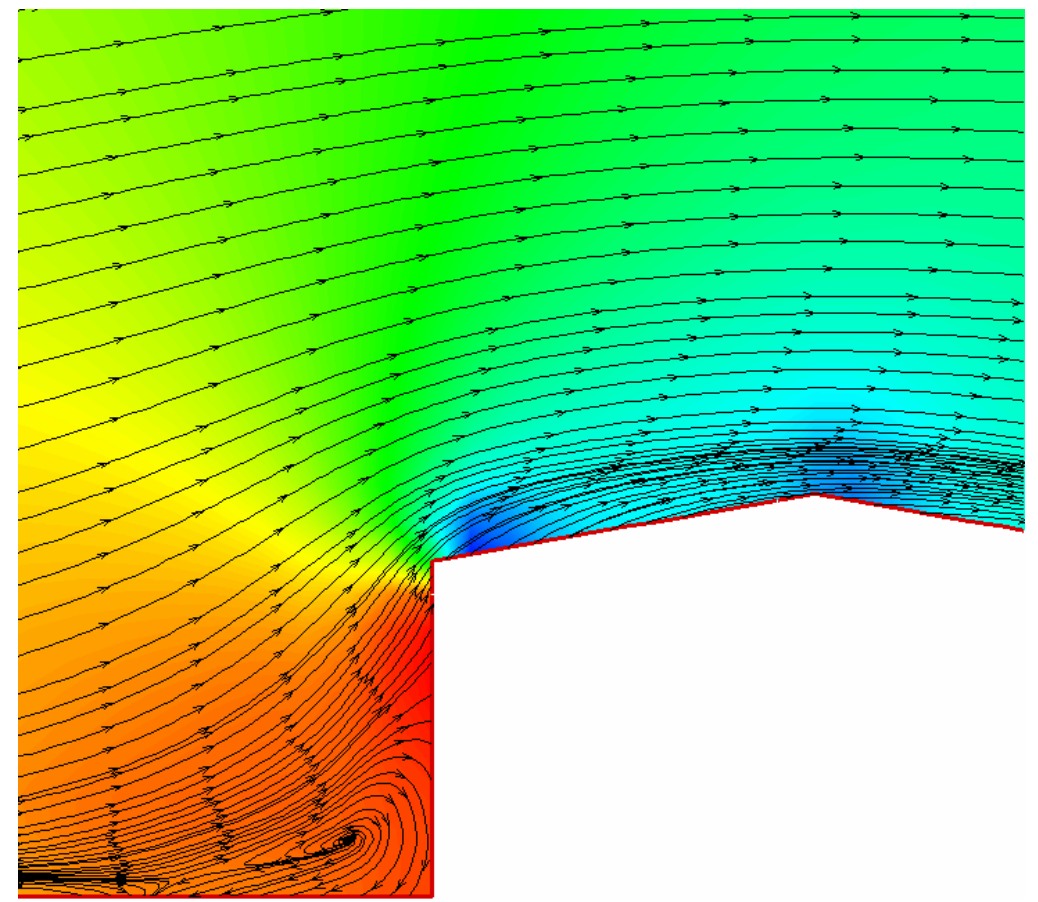

Figure 6 The Generated Streamlines for Gable Roof Corner and Ridge

\section{Results and Discussions}

\subsection{TTU building}

The pressure coefficients obtained in the present study for the TTU building model have been compared with the pressure coefficients obtained by Cochran (1992) in a wind tunnel testing on TTU building model on a geometric scale of 1:100.

The three faces of the building are termed as front wall, roof, and rear wall. A graphical comparison has been made between the pressure coefficients on the edge of all these faces throughout its length.

The pressure coefficients follow a similar trend with the Cocharan results at the front wall, roof and rear wall which have been shown in Figures 7,8 with an average variation of 20\%, 10\% and 35\% respectively. The Reynold's number in the present study is same as prototype, whereas it is less in wind tunnel simulation, that's why the error at corner point of the bluff body is more. Also, in the past Tieleman (1996) pointed out that the magnitude of the fluctuating pressure coefficients $\left(C_{p}\right.$ rms and $C_{p}$ peak $)$ obtained from the wind tunnel simulation experiments exhibit invariably a great deal of scatter and generally underestimate the field results. Rofail (1995) made a comparative study between Wintech Boundary layer wind tunnel and full scale measurements, as well as model scale measurements at Colorado State University (CSU) and found that the peak rms pressure coefficients as predicted by Wintech were within 10 percent for the wall pressure data and within 4 percent for the roof pressures. For Peak negative pressure for corner tap, Wintech's results underestimate the full scale data by approximately 25 percent. This is a significant result improvement over the CSU results which underestimate the full scale data by approximately 50 percent for the same corner tap.

The deviation in the results at the corner points shows that there is lack of simulation of the flow at the corners. In the wind tunnel testing also the peak pressure coefficients at the corner point do not match with the TTU Field value. The difference in the values of pressure coefficients may be attributed to (i) for most accurate results $3 \mathrm{D}$ simulation is required. This requires super computer for its processing. Time required in one run is also too high, approximately 30 hours, which is not possible in the present study, (ii) the nature of flow is highly unpredictable due to large eddies and vortex formation at the edges and there is a large possibility of lack of simulation of flow in such a case. The pressure coefficients at the edges are hence showing a deviation.

\subsection{Gable roof}

The results of the pressure coefficients obtained in the present study for $10^{\circ}, 20^{\circ}$ and $30^{\circ}$ gable roof structures have been compared with the results of Mathews et al. (1988) on gable structures for $15^{\circ}, 26^{\circ}$ and $35^{\circ}$ roof slopes.

The four faces of the structure are named as front wall, front roof, rear roof and rear wall. A graphical comparison has been done between the pressure coefficients on the edge of all these faces throughout its length.

In comparison between $10^{\circ}$ (Present study) and $15^{\circ}$ (Mathews), the front wall and front roof pressure coefficients follow a similar pattern (Figures 9,10 ) with an average variation of $17 \%$ and $22 \%$ respectively which reduces towards the end of the face i.e. at the top of the front wall and at the ridge. 
The pressure coefficients follow a similar trend at the rear roof (Figure 10) except at the start of the face i.e. at the top of the structure. The average deviation is $25 \%$.

The rear wall values of pressure coefficients (Figure 9) show an average variation of $15 \%$ which decreases gradually towards the end of the face i.e. at the bottom of the rear wall.

On comparing between $20^{\circ}$ (Present study) and $26^{\circ}$ (Mathews), the pressure coefficients for the front wall (Figure 11) follow a similar trend and the variation between the values reduces gradually with an average of $10 \%$.

The curves for the front roof (Figure 12) show a large variation. The average variation is $35 \%$. This high variation is due to difference in roof angles.

The pressure coefficients for the rear roof and rear wall (Figures 11,12) match fairly and both follow the same trend. In rear roof, except at the start of the face, i.e. at the roof top, all the values of $20^{\circ}$ are similar to those of $26^{\circ}$. The average difference is $20 \%$. The pressure coefficients for the rear wall have an average variation of $10 \%$. The variation between the pressure coefficients of the $20^{\circ}$ and $26^{\circ}$ decreases gradually to the end of the face i.e. at the bottom of the rear wall.

In comparison between $30^{\circ}$ (Present study) and $35^{\circ}$ (Mathews), the front wall pressure coefficient values for $30^{\circ}$ and $35^{\circ}$ (Figure 13) follow the same trend. The average difference is found to be about $15 \%$.

The pressure coefficient curves for the front roof and rear roof (Figure 14) for $30^{\circ}$ and $35^{\circ}$ gable structures show nearly similar shape with a constant difference in between except at the ridge region. The average variation is $35 \%$ and $20 \%$ respectively for front and rear roof.

The values for the rear wall for $30^{\circ}$ and $35^{\circ}$ (Figure 13) also show a similar trend. There is a small difference in between them which goes on decreasing along the face length and the curves intersect at the end i.e. at the bottom level of the rear wall. The average variation is $10 \%$.

The similar error variations between $10^{\circ}$ and $15^{\circ}, 20^{\circ}$ and $26^{\circ}$ and $30^{\circ} \& 35^{\circ}$ show that there is an appreciable agreement between the pressure coefficients of the gable roof model used in the present study and the model used by Mathews et al. (1988).

\section{Conclusions}

The results obtained by the present study shows that the 2-D simulation using k- $\varepsilon$ model for TTU building agree fairly well (except at corner points) with the results of wind tunnel data whereas present study and Mathews et al. for Gable roof buildings match well at all the points as the variations in results are uniform for $5^{\circ}$ roof slope variation. The average variation in results between present study and wind tunnel testing results of Cocharan on 1:100 geometric scale on front wall, roof and rear wall of TTU building model are $20 \%, 15 \%$ and $35 \%$ respectively. The average variation in results amongst present study $\left(10^{\circ}\right)$ and Mathews $e t$ al. $\left(15^{\circ}\right)$ on gable roof is between $17 \%$ to $25 \%$ for difference of $5^{\circ}$ roof slopes. The average variation in results amongst present study $\left(20^{\circ}\right)$ and Mathews et al. $\left(26^{\circ}\right)$ on gable roof is between $10 \%$ to $35 \%$ for difference of $6^{\circ}$ roof slopes. The average variation in results amongst present study $\left(30^{\circ}\right)$ and Mathews et al. $\left(35^{\circ}\right)$ on gable roof is between $15 \%$ to $35 \%$ for difference of $5^{\circ}$ roof slopes. The discrepancies in the pressure coefficient variations of TTU building model with wind tunnel testing results are due to the improper simulation in $2 \mathrm{D}$. 


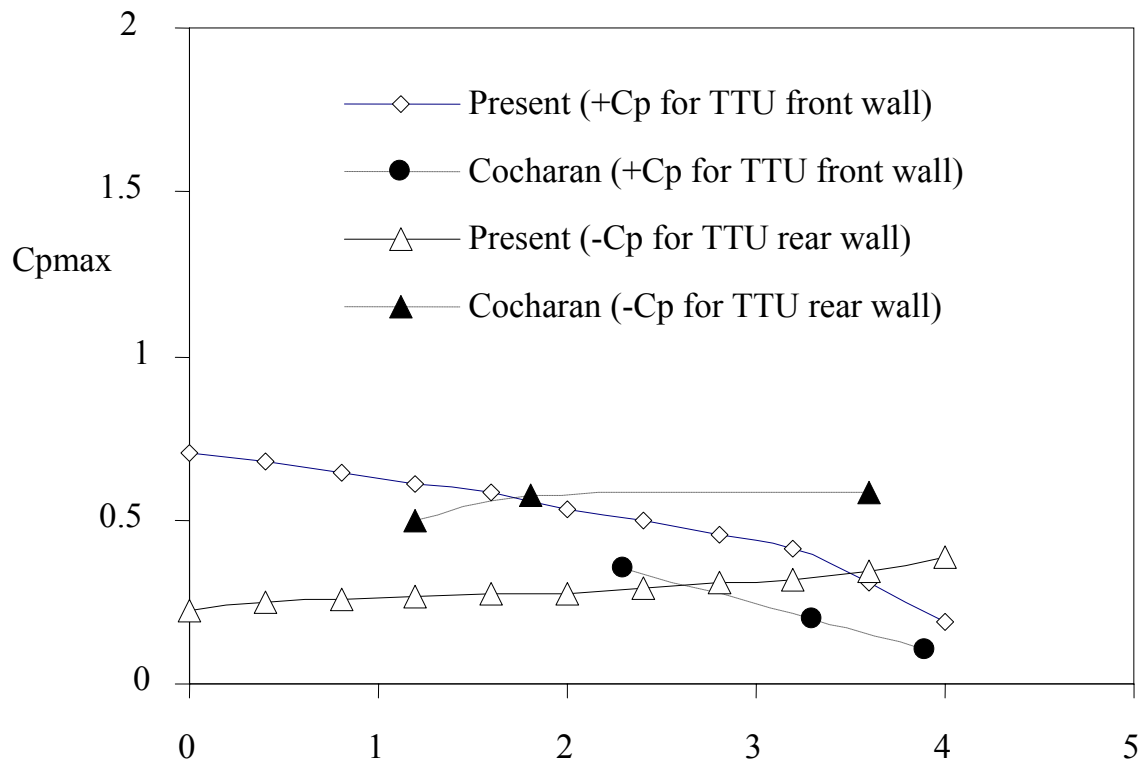

Distance from bottom to eave (m)

Figure 7 Comparison of pressure coefficients for walls on TTU building

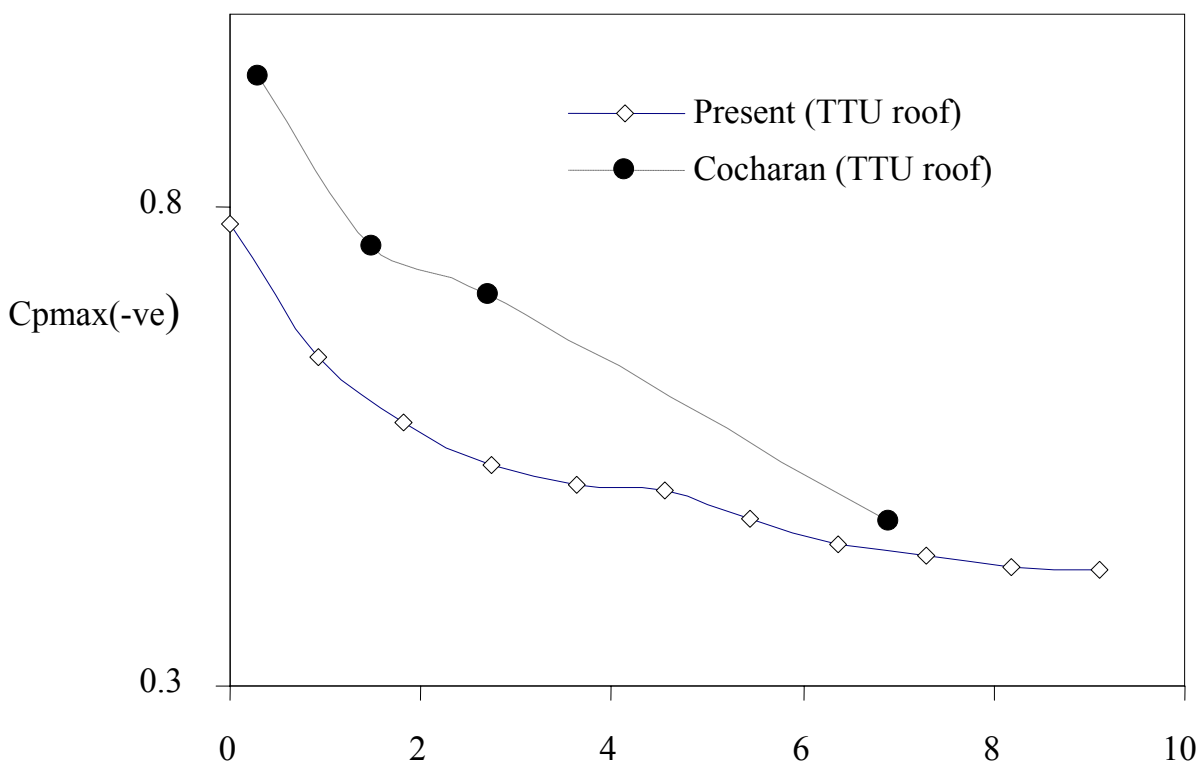

Distance from front wall edge to rear wall edge (m)

Figure 8 Comparison of pressure coefficients for roofs on TTU building 


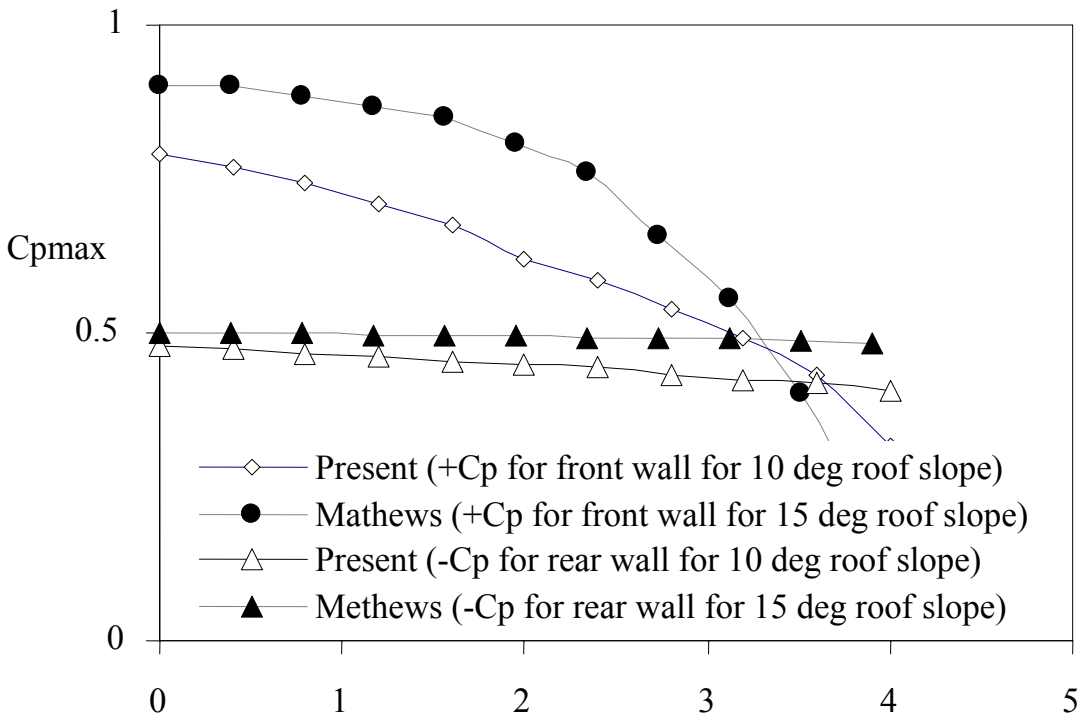

Distance from bottom to eave (m)

Figure 9 Comparison of pressure coefficients for walls on gable roof building for $10^{\circ}$ roof slope

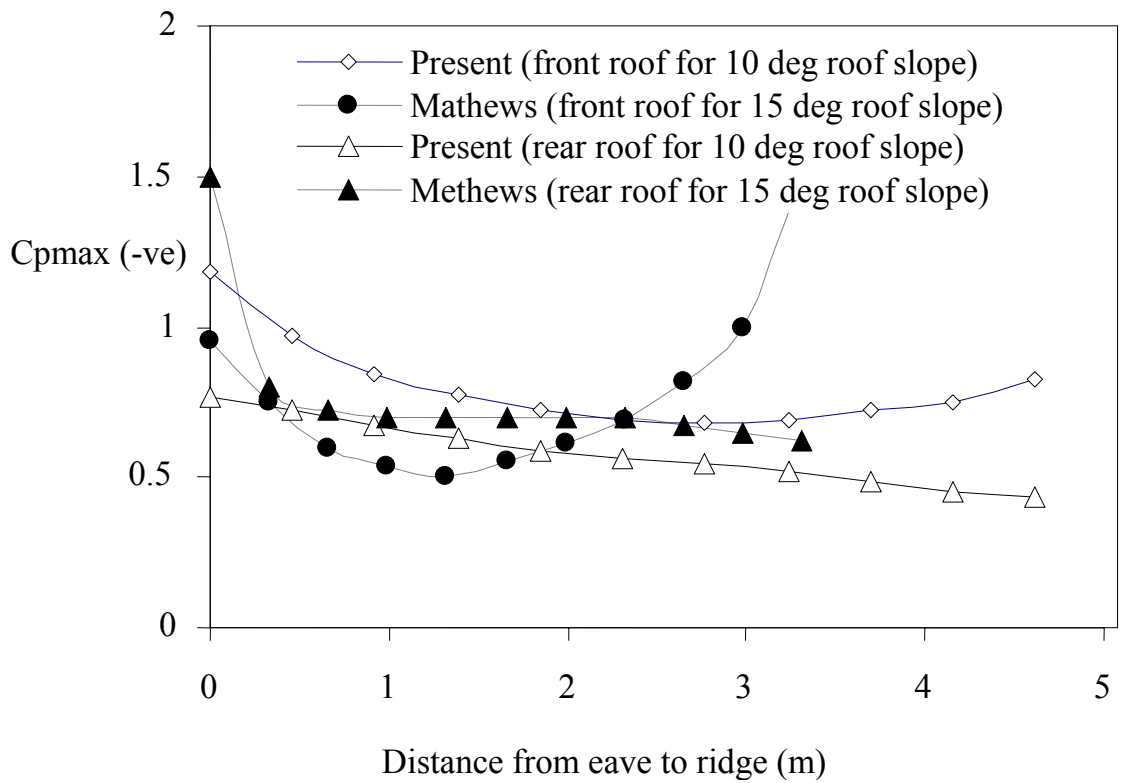

Figure 10 Comparison of pressure coefficients for roofs on gable roof building for $10^{\circ}$ roof slope 


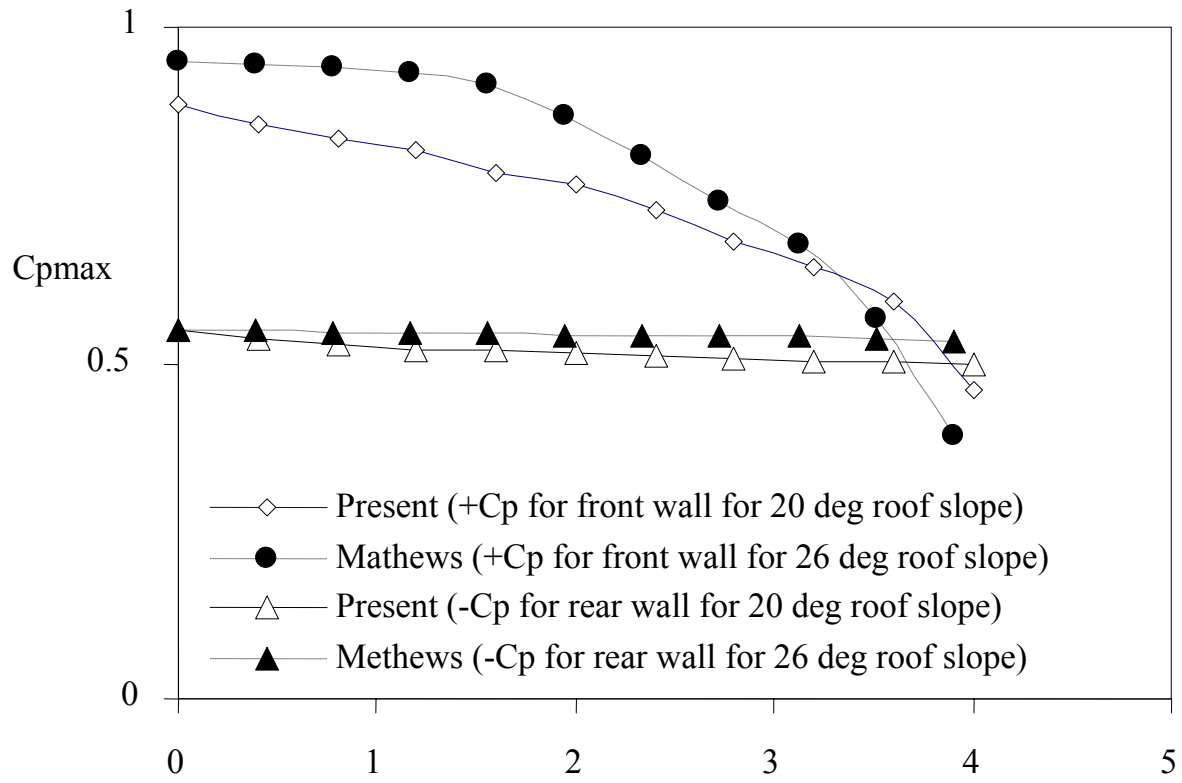

Distance from bottom to eave (m)

Figure 11 Comparison of pressure coefficients for walls on gable roof building for $20^{\circ}$ roof slope

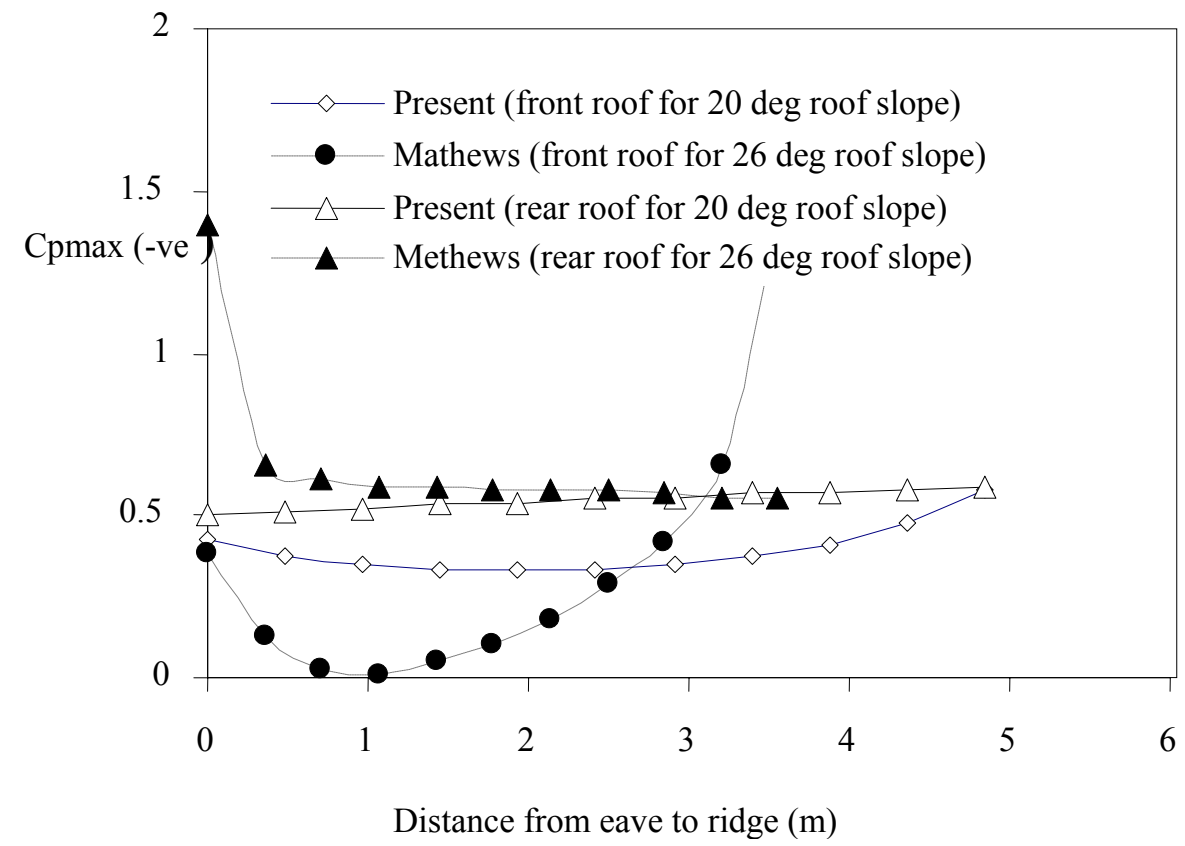

Figure 12 Comparison of pressure coefficients for roofs on gable roof building for $20^{\circ}$ roof slope 


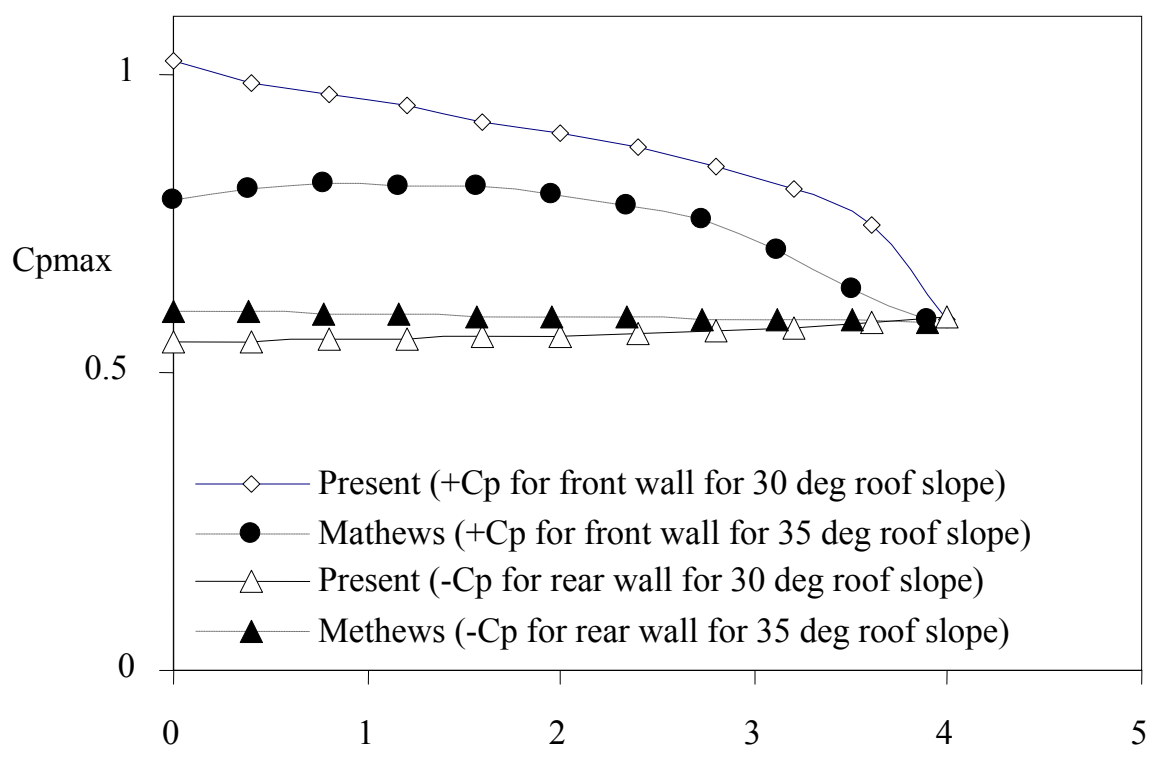

Distance from bottom to eave (m)

Figure 13 Comparison of pressure coefficients for walls on gable roof building for $30^{\circ}$ roof slope

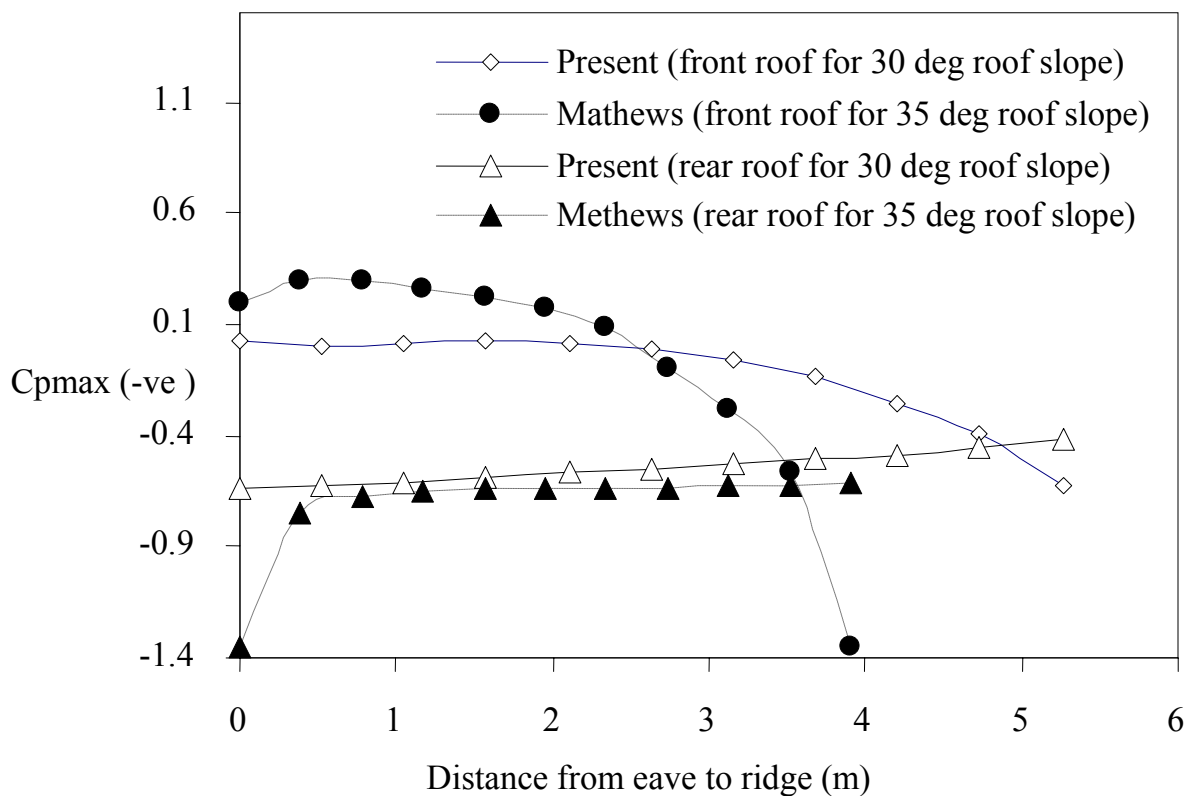

Figure 14 Comparison of pressure coefficients for roofs on gable roof building for $30^{\circ}$ roof slope 


\section{Nomenclature}

$\begin{array}{ll}\text { TTU } & \text { Texas Tech University } \\ \circ & \text { Degree } \\ \mathrm{Re} & \text { Reynolds number } \\ \text { 3D } & \text { Three-dimensional } \\ \text { 2D } & \text { Two-dimensional } \\ \mathrm{CFD} & \text { Computational Fluid Dynamics } \\ \rho & \text { Density } \\ \mathrm{V} & \text { Velocity Vector } \\ D / D t & \text { Substantial Derivative } \\ \mathrm{P} & \text { Pressure } \\ \mu & \text { Effective Viscosity } \\ \mathrm{k}_{\mathrm{s}} & \text { Surface Roughness Parameter } \\ \mathrm{u}_{\mathrm{ref}} & \text { Mean horizontal wind speed } \\ \mathrm{u}(\mathrm{y}) & \text { Mean horizontal wind speed distribution as a function of height y } \\ \mathrm{L}(\mathrm{y}) & \text { Turbulence length scale at height y } \\ \alpha & \text { Power Law Coefficient } \\ \mathrm{C}_{\mathrm{p} \text { peak }} & \text { Pressure Coefficient (Peak) } \\ \mathrm{C}_{\mathrm{p} \text { rms }} & \text { Pressure Coefficient (Root Mean Square) } \\ \mathrm{Cp}_{\max } & \text { Maximum Pressure Coefficient } \\ \mathrm{Cp}_{\max (-v e)} \text { Maximum Negative Pressure Coefficient }\end{array}$

\section{References}

Baskaran, A. and Stathopoulos, T. (1989). Computational evaluation of wind effects on buildings. Building and Environment Journal, Vol. 24, No: 4, pp: 325-333.

Cochran, L.S. (1992).Wind tunnel modelling of low-rise structures. Ph.D. Thesis, Colorado State University, USA.

Crosby, C. P., Mathews, E. H., and Du Plessis, J. P. (1990).The numerical prediction of air flow through and around permeable windbreaks and buildings. Journal of Wind Engineering and Industrial Aerodynamics, Vol. 35, No: 1-3, pp: 213-224.

Frank, W. (1996).Three-dimensional numerical calculation of the turbulent flow around a sharp-edged body by means of largeeddy-simulation. Journal of Wind Engineering and Industrial Aerodynamics, Vol. 65, No: 1-3, pp: 415-424.

Frank, W. and Mauch H. (1993).Large-eddy-simulation of the flow around building models. Journal of Wind Engineering and Industrial Aerodynamics, Vol. 46-47, pp: 213-218.

Gao, Y., and Chow, W.K. (2005).Numerical studies on air flow around a cube. Journal of Wind Engineering and Industrial Aerodynamics, Vol. 93, No: 2, pp: 115-135.

Ghosh, A.K. (2004).Computational Wind Engg.- Prospects and Challenges. International workshop on wind engineering and science (WES-04), Elite Publishing House Pvt. Ltd., New Delhi, pp 107-120.

Hoffman, J. and Johnson, C. (2006).A new approach to computational turbulence modeling. Computer Methods in Applied Mechanics and Engineering, Vol. 195, No: 23-24, pp: 2865-2880.

Huang, S., Li, Q.S. and Xu, S. (2007).Numerical evaluation of wind effects on a tall steel building by CFD. Journal of Constructional Steel Research, Vol. 63, No: 5, pp: 612-627.

Kondo, K., Murakami, S. and Mochida, A. (1997).Generation of velocity fluctuations for inflow boundary condition of LES. Journal of Wind Engineering and Industrial Aerodynamics, Vol. 67-68, pp: 51-64.

Lakehal, D. and Rodi, W. (1997).Calculation of the flow past a surface-mounted cube with two-layer turbulence models. Journal of Wind Engineering and Industrial Aerodynamics, Vol. 67-68, pp: 65-78.

Mathews, E. H. and Meyer, J. P. (1987).Numerical modeling of wind loading on a film clad greenhouse. Building and Environment, Vol. 22, No: 2, pp: 129-134.

Mathews, E. H., Crosby, C. P., Visser, J. A. and Meyer, J. P. (1988).Numerical prediction of wind loads on buildings. Journal of Wind Engineering and Industrial Aerodynamics, Vol. 31, No: 2-3, pp: 241-250.

Mochida, A., Murakami, S., Shoji, M., Ishida, Y. (1993).Numerical Simulation of flow field around Texas Tech Building by Large Eddy Simulation. Journal of Wind Engineering and Industrial Aerodynamics, Vol. 46-47, pp: 455-460.

Murakami, S. (1990).Numerical simulation of turbulent flow field around cubic model current status and applications of $k-\varepsilon$ model and LES. Journal of Wind Engineering and Industrial Aerodynamics, Vol. 33, No: 1-2, pp: 139-152.

Murakami, S. (1993).Comparison of various turbulence models applied to a bluff body. Journal of Wind Engineering and Industrial Aerodynamics, Vol. 46-47, pp: 21-36.

Murakami, S. and Mochida, A. (1995).On turbulent vortex shedding flow past 2D square cylinder predicted by CFD.Journal of Wind Engineering and Industrial Aerodynamics, Vol. 54-55, pp: 191-211. 
Murakami, S., Iizuka, S. and Ooka, R. (1999).CFD analysis of turbulent flow past square cylinder using dynamic LES. Journal of Fluids and Structures, Vol. 13, No: 7-8, pp: 1097-1112.

Murakami, S., Mochida, A. and Sakamoto, S. (1997).CFD analysis of wind-structure interaction for oscillating square cylinders. Journal of Wind Engineering and Industrial Aerodynamics, Vol. 72, pp: 33-46.

Nozawa, K. and Tamura, T. (2002).Large eddy simulation of the flow around a low-rise building immersed in a rough-wall turbulent boundary layer. Journal of Wind Engineering and Industrial Aerodynamics, Vol. 90, No: 10, pp: 1151-1162.

Paterson, D.A. and Papen fuss, A. T. (1993).Computation of wind flows around two tall buildings. Journal of Wind Engineering and Industrial Aerodynamics, Vol. 50, pp: 69-74.

Richards, P. J. and Hoxey, R. P. (1993).Appropriate boundary conditions for computational wind engineering models using the k- $\varepsilon$ turbulence model. Journal of Wind Engineering and Industrial Aerodynamics, Vol. 46-47, pp: 145-153.

Rodi, W. (1993).On the simulation of turbulent flow past bluff bodies. Journal of Wind Engineering and Industrial Aerodynamics, Vol. 46-47, pp: 3-19.

Rofail, A. W. (1995).Full scale/model-scale comparisons of wind pressures on the TTU building, 9ICWE, New Delhi, pp 10551066.

Sakamoto, S., Murakami, S., Kato, S., Mochida, A. (1993).Unsteady pressure field around oscillating prism predicted by LES.Journal of Wind Engineering and Industrial Aerodynamics, Vol. 46-47, pp: 551-556.

Shah, K. B. and Ferziger, J. H. (1997).A fluid Mechanician's view of wind engineering: Large eddy simulation of flow past a cubic obstacle. Journal of Wind Engineering and Industrial Aerodynamics, Vol. 67-68, pp: 211-224.

Stathopoulos, T. and Baskaran, A. (1990).Boundary treatment for the computation of three-dimensional wind flow conditions around a building. Journal of Wind Engineering and Industrial Aerodynamics, Vol. 35, pp: 177-200.

Stathopoulos, T. and Saathoff, P. (1991).Wind pressure on roofs of various geometries. Journal of Wind Engineering and Industrial Aerodynamics, Vol. 38, pp: 273-284.

Stathopoulos, T. and Zhou, Y. S. (1993).Numerical simulation of wind-induced pressures on buildings of various geometries. Journal of Wind Engineering and Industrial Aerodynamics, Vol. 46-47, pp: 419-430.

Stathopoulos, T. and Zhou, Y. S. (1995).Numerical evaluation of wind pressures on flat roofs with the $k-\varepsilon$ model. Journal of Building and Environment, Vol. 30, pp: 267-276.

Tieleman, H. W. (1996).Model/full scale comparison of pressures on the roof of the TTU experimental building. Journal of Wind Engineering and Industrial Aerodynamics, Vol. 65, pp: 133-142.

Tominaga, Y., Murakami, S. and Mochida, A. (1997).CFD prediction of gaseous diffusion around a cubic model using a dynamic mixed SGS model based on composite grid technique. Journal of Wind Engineering and Industrial Aerodynamics, Vol. 67-68, pp: 827-841.

Tsuchiya, M., Murakami, S., Mochida, A., Kondo K. and Ishida, Y. (1997).Development of a new $k-\varepsilon$ model for flow and pressure fields around bluff body. Journal of Wind Engineering and Industrial Aerodynamics, Vol. 67-68, pp: 169-182.

$\mathrm{Yu}, \mathrm{D}$. and Kareem, A. (1996). Two-dimensional simulation of flow around rectangular prisms. Journal of Wind Engineering and Industrial Aerodynamics, Vol. 62, No: 2-3, pp: 131-161.

$\mathrm{Yu}$, Da Hai and Kareem, A. (1998).Parametric study of flow around rectangular prisms using LES. Journal of Wind Engineering and Industrial Aerodynamics, Vol. 77-78, pp: 653-662.

Zaheer, I. (2007). Numerical prediction of wind loads on buildings. M. Tech. Dissertation, Department of Civil Engineering, Aligarh Muslim University, Aligarh (India).

Received August 2010

Accepted March 2011

Final acceptance in revised form May 2011 